\title{
Asparagus officinalis extract controls blood glucose by improving insulin secretion and $\beta$-cell function in streptozotocin-induced type 2 diabetic rats
}

\author{
Rahman Md. Hafizur*, Nurul Kabir and Sidra Chishti \\ Dr Panjwani Center for Molecular Medicine and Drug Research, International Center for Chemical and Biological Sciences, \\ University of Karachi, Karachi 75270, Pakistan
}

(Submitted 13 July 2011 - Final revision received 23 November 2011 - Accepted 23 November 2011 - First published online 6 January 2012)

\begin{abstract}
The aim of the present study was to evaluate the anti-diabetic mechanism of Asparagus officinalis, a dietary agent used for the management of diabetes. Streptozotocin $(90 \mathrm{mg} / \mathrm{kg}$ ) was injected in 2-d-old Wistar rat pups to induce non-obese type 2 diabetes. After confirmation of diabetes on the 13th week, diabetic rats were treated with a methanolic extract of $A$. officinalis seeds ( $250 \mathrm{and} 500 \mathrm{mg} / \mathrm{kg}$ per $\mathrm{d})$ or glibenclamide for $28 \mathrm{~d}$. After the treatment, fasting blood glucose, serum insulin and total antioxidant status were measured. The pancreas was examined by haematoxylin-eosin staining and immunostained $\beta$ - and $\alpha$-cells were observed using a fluorescence microscope. Treatment of the diabetic rats with the A. officinalis extract at doses of 250 and $500 \mathrm{mg} / \mathrm{kg}$ suppressed the elevated blood glucose in a dose- and time-dependent manner. The $500 \mathrm{mg} / \mathrm{kg}$, but not $250 \mathrm{mg} / \mathrm{kg}$, dose significantly improved serum insulin levels in the diabetic rats. The insulin:glucose ratio was significantly increased at both doses in the $A$. officinalis-treated rats. Both qualitative and quantitative improvements in $\beta$-cell function were found in the islets of the $A$. officinalis-treated rats. The extract showed potent antioxidant activity in an in vitro assay and also improved the total antioxidant status in vivo. In most cases, the efficacy of $A$. officinalis $(500 \mathrm{mg} / \mathrm{kg}) \mathrm{was}$ very similar to a standard anti-diabetic drug, glibenclamide. Thus, the present study suggests that $A$. officinalis extract exerts anti-diabetic effects by improving insulin secretion and $\beta$-cell function, as well as the antioxidant status.
\end{abstract}

Key words: Asparagus officinalis: Neonatal streptozotocin-induced type 2 diabetes: Insulin secretion: $\beta$-Cell function: Antioxidant status

Diet (nutrition) plays an important role in the management of diabetes, and for preventing and/or delaying the development of type 2 diabetes. Dietary approaches can be used alone (in the case of the onset of type 2 diabetes and in mild hyperglycaemia) or in combination with oral hypoglycaemic agents or insulin. Often, the success or failure of the management of diabetes depends on the knowledge of the diabetic patient regarding the dietary principles related to diabetes. Although there have been major advances in the control of diabetes through oral hypoglycaemic agents and insulin, the management of diabetes by dietary agents such as vegetables, fruits and spices is more appropriate and economical in developing countries such as Pakistan. There is an inverse association between vegetable consumption and chronic disease reduction, such as cancer, CVD and diabetes ${ }^{(1-3)}$.

Asparagus officinalis $\mathrm{L}$. is a dietary agent native to most European, African and Asian countries. Its medicinal usage has been reported in the British and Indian Pharmacopoeias and in traditional systems of medicine such as Ayurveda,
Unani and Siddha. Asparagus has been used as a vegetable and medicine in many countries, owing to its delicate flavour and diuretic properties. Asparagus is frequently used in salads, vegetable dishes and soups. Green asparagus is a good source of vitamin $\mathrm{C}$ and its stalks are rich in antioxidants. Among the vegetables commonly consumed in the USA and Europe, asparagus has been reported to be a rich source of antioxidants, in terms of both quality and quantity ${ }^{(4,5)}$. In a comparative study among thirty-four fruits and vegetables ${ }^{(5)}$, asparagus has been placed 7 th in the rank of radical scavengers and 13th in ferric-reducing power.

The chemical constituents of $A$. officinalis have been studied to some extent. The compounds so far reported include saponins $^{(6,7)}$, saccharides ${ }^{(8-10)}$, acetylenic compounds ${ }^{(11)}$ and sulphur-containing compounds ${ }^{(12-15)}$. Various reports have suggested that polysaccharides derived from this plant exhibit antioxidant properties ${ }^{(16-18)}$. To our knowledge, there are no studies reporting on any identified compound isolated from A. officinalis as an anti-diabetic.

\footnotetext{
Abbreviations: $\mathrm{AO}_{250}$, diabetic rats treated with $250 \mathrm{mg} / \mathrm{kg}$ Asparagus officinalis extract; $\mathrm{AO}_{500}$, diabetic rats treated with $500 \mathrm{mg} / \mathrm{kg}$ Asparagus officinalis extract; DAPI, 4',6-diamidino-2-phenylindole; Db, untreated diabetic rats; DPPH, 1,1-diphenyl-2-picrylhydrazyl; GB, glibenclamide; H\&E, haematoxylin and eosin; n-STZ, neonatal streptozotocin-induced; STZ, streptozotocin; TAS, total antioxidant status.
} 
Studies on the extracts of $A$. officinalis have revealed a wide range of biological activities including diabetes ${ }^{(19)}$. These activities include anti-tumour ${ }^{(20)}$, antifungal ${ }^{(21)}$, diuretic ${ }^{(22)}$ and immunostimulatory effects ${ }^{(23,24)}$. Asparagus has also been shown to exert potent antioxidant properties ${ }^{(25)}$. It has been claimed by traditional healers that the seeds of A. officinalis have anti-diabetic properties ${ }^{(26)}$.

A. officinalis was reported for the first time for treating diabetes in a survey conducted in the West Bank region of Israel $^{(19)}$. Recently, Zhao et al. ${ }^{(27)}$ reported that the aqueous extract of the by-products of $A$. officinalis exerts anti-diabetic activity in streptozotocin (STZ)-induced diabetic rats. In their study, only the blood glucose-lowering effect coupled with hypotriacylglycerolaemic activity has been shown. However, the precise anti-diabetic mechanism has not yet been elucidated. Most importantly, there has been no morphological study observing the pancreatic islets and $\beta$-cells in diabetic rats treated with $A$. officinalis.

STZ-induced diabetes has been widely used to study the pathophysiology of diabetes. The induction of STZ during adulthood produces severe diabetes that often needs insulin administration to ensure survival for longer periods. In the case of neonatal STZ-induced (n-STZ) rats, the development of hyperglycaemia, abnormal glucose tolerance and mild hypoinsulinaemia is an insidious process that is almost asymptomatic at the beginning and becomes manifested in the adult stage, the features that resemble the natural history of diabetes in humans ${ }^{(28,29)}$. The $\mathrm{n}$-STZ diabetic rats have similar insulin secretory characteristics to those found in non-obese type 2 diabetic subjects ${ }^{(30,31)}$. Thus, the $\mathrm{n}$-STZ model is considered to be one of the suitable experimental animal models for non-obese type 2 diabetes for testing potential anti-diabetic agents.

The present study was conducted to investigate the effect of A. officinalis on insulin secretion and pancreatic $\beta$-cell function in n-STZ non-obese type 2 diabetic rats by measuring blood glucose, serum insulin and total antioxidant status (TAS). In addition, morphological examination of the pancreas was also performed to further substantiate the beneficial effect of $A$. officinalis on pancreatic $\beta$-cell function. The immunohistochemical method for the triple staining of insulin, glucagon and the nuclei was combined with morphometrical analysis. The efficacy of $A$. officinalis was compared with a standard anti-diabetic drug, glibenclamide.

\section{Materials and methods}

\section{Materials}

STZ and glibenclamide were obtained from Sigma; Insulin ELISA kit from Crystal Chem, Inc.; TAS kit from Randox. Insulin (guinea-pig anti-insulin) antibody was from Abcam and glucagon (mouse anti-glucagon, Clone K79bB10) from Sigma. The fluorescent-labelled secondary antibodies, Texas Red-donkey anti-guinea-pig IgG and Cy2-donkey anti-mouse IgG were obtained from Jackson ImmunoResearch. 4',6-Diamidino-2-phenylindole (DAPI) was obtained from Wako Pure Chemical.

\section{Preparation of the extract}

Seeds of $A$. officinalis ( $1 \mathrm{~kg}$ ) were bought from a local market in Karachi, Pakistan. The plant material belongs to Drosh City, Chitral District, Khyber-Pakhtunkhwa, Pakistan. The seeds were authenticated by a taxonomist at the University of Karachi, and a voucher specimen (no. 73960) was deposited at the Karachi University Herbarium, Pakistan. The powdered seeds were soaked twice in 3 litres of $80 \%$ aqueous methanol for $72 \mathrm{~h}$ at room temperature. The pooled extracts were filtered, concentrated and evaporated to dryness under vacuum by using a rotary evaporator. Finally, the crude extract was freeze-dried to obtain the experimental extract $(76.5 \mathrm{~g})$. The extract was dissolved in distilled water before its administration to the diabetic rats. The extract yield was $7 \cdot 6 \%$.

\section{In vitro studies}

1,1-Diphenyl-2-picrylhydrazyl radical-scavenging activity assay. The radical-scavenging property of the extract was evaluated by assessing the 1,1-diphenyl-2-picrylhydrazyl (DPPH)-scavenging activity according to Fenglin et al. ${ }^{(32)}$. Propyl gallate was used as a positive control.

$\alpha$-Glucosidase inhibitory assay. An in vitro assay for $\alpha$-glucosidase inhibitory activity was performed according to Atta-urRahman et al. ${ }^{(33)}$. Acarbose was used as a positive control.

\section{In vivo studies}

Animals. Wistar rats of both sexes obtained from the animal house of the International Center for Chemical and Biological Sciences, University of Karachi, Pakistan were used throughout the study. The animals were kept in a temperature- and humidity-controlled environment $\left(25 \pm 2^{\circ} \mathrm{C} ; 50-55 \%\right.$ humidity, respectively) with a $12 \mathrm{~h}$ light $-12 \mathrm{~h}$ dark cycle. The rats were maintained in clean cages with ad libitum access to water and food. The experimental design of the present study was conducted according to the guidelines for care and management of laboratory animals, and the animal experimental protocol was approved by the institutional animal ethical committee.

Induction of type 2 diabetes. A freshly prepared solution of STZ $(90 \mathrm{mg} / \mathrm{kg})$ in $10 \mathrm{ml}$ citrate buffer $(0 \cdot 1 \mathrm{M}, \mathrm{pH} 4.5)$ was intraperitoneally injected to 2 -d-old Wistar rat pups to obtain type 2 diabetic rat models ${ }^{(34)}$. After 12 weeks of STZ induction, an oral glucose tolerance test at a dose of $3 \mathrm{~g} / \mathrm{kg}$ glucose was performed and blood glucose was measured at 0, 30, 60 and $120 \mathrm{~min}$, respectively. The rats with fasting blood glucose levels of $7 \cdot 6-10.9 \mathrm{mmol} / \mathrm{l}$ at $0 \mathrm{~min}$ and the highest rise to $12 \cdot 5-22 \cdot 1 \mathrm{mmol} / 1$ at $30 \mathrm{~min}$ were included in the study. Blood was withdrawn from the tail tip every week to measure blood glucose levels using a glucometer (Accu-Chek ${ }^{\circledR}$ Go; Roche Diagnostics).

Chronic extract treatment. The experimental rats were divided into five groups of six animals each: age-matched non-diabetic control that did not receive STZ (group I); diabetic rats without any treatment ( $\mathrm{Db}$, group II); diabetic rats treated with $A$. officinalis at a dose of $250 \mathrm{mg} / \mathrm{kg}\left(\mathrm{Db}+\mathrm{AO}_{250}\right.$, group III); diabetic rats treated with $A$. officinalis at a dose of 
$500 \mathrm{mg} / \mathrm{kg}\left(\mathrm{Db}+\mathrm{AO}_{500}\right.$, group IV); diabetic rats treated with $5 \mathrm{mg}$ glibenclamide/kg ( $\mathrm{Db}+\mathrm{GB}$, group $\mathrm{V})$. The extract and GB were administered orally once daily via syringe for $28 \mathrm{~d}$ to the diabetic rats. The control rats were given an equivalent volume of water. Animal weights were measured every week throughout the experiment and the dose was adjusted accordingly.

Collection of blood samples and estimation of biochemical parameters. At 13 weeks after the administration of STZ, blood samples from overnight fasted rats of each group were collected from the tail vein and the day was designated as day 1 (start day of the treatment). After $28 \mathrm{~d}$ of the extract treatment, i.e. on day 29, rats were anaesthetised (sodium thiopental, $60 \mathrm{mg} / \mathrm{kg}$ ) and killed, and their venous blood was collected. The blood samples were centrifuged, and serum was separated within $30 \mathrm{~min}$, divided into aliquots and kept at $-80{ }^{\circ} \mathrm{C}$ for biochemical assay. Thereafter, the pancreas was carefully and rapidly excised, trimmed of fat and adipose tissue, and fixed in $10 \%$ neutral buffered formalin overnight. Then, all the formalin-fixed tissues were dehydrated in graded 2 -propanol series and cleared with xylene. This was immediately followed by paraffin embedding using an embedding system. The tissues were cut into $5 \mu \mathrm{m}$ serial sections with a microtome for haematoxylin-eosin (H\&E) and immunohistochemical staining, and mounted on slides coated with gelatin.

Fasting serum glucose was measured by the glucose oxidase method (\%CV 5.43\%) and fasting serum insulin was measured using the Ultra Sensitive Rat Insulin ELISA kit (\%CV $3.95 \%$ ) on days 1 and 29 , according to the manufacturer's protocol. TAS was measured using the ABTS ${ }^{\circledR}$ substrate assay kit (\%CV 2.88\%) according to the manufacturer's instruction (Randox). Serum creatinine, alanine aminotransferase and aspartate aminotransferase were measured by standard techniques using the Reflotron ${ }^{\circledR}$ Plus Dry Chemistry Analyzer (Roche Diagnostics).

\section{Microscopic examination}

Haematoxylin and eosin staining. For H\&E staining, sections were deparaffinised in xylene, rehydrated in graded 2-propanol series and washed in water. The sections were then stained with H\&E. Pancreatic sections were visualised using a Nikon 90i microscope (Nikon) and the images were acquired with a Nikon DXM 1200C camera using NIS-Elements image analysis software AR 3.0 (Nikon).

Immunohistochemical staining. For immunohistochemical staining, six sections in different planes from each rat were triple stained for insulin, glucagon and nuclei. For this purpose, the sections were deparaffinised, rehydrated, washed in water and subjected to antigen retrieval $\left(90^{\circ} \mathrm{C}\right.$ for $\left.30 \mathrm{~min}\right)$ in $0 \cdot 1 \mathrm{~m}$-citrate buffer ( $\mathrm{pH} 6 \cdot 0$ ). After cooling to room temperature, each section was incubated with a blocking solution (2\% normal donkey serum in PBS) for $10 \mathrm{~min}$ at room temperature. Then, each section was incubated with a mixture of guinea-pig anti-insulin (1:100) and mouse anti-glucagon (1:1500) for $1 \mathrm{~h}$. After washing with PBS, the sections were incubated with a mixture of Texas Red-conjugated donkey anti-guinea-pig IgG (1:100) and Cy2-conjugated donkey anti-mouse $\operatorname{IgG}(1: 100)$ for $30 \mathrm{~min}$. The nuclei were stained with DAPI, washed with PBS and mounted in Fluoromount solution (Sigma). The fluorescent images were visualised using a Nikon TE2000E fluorescent microscope equipped with a Nikon DS-2MBWc camera in DAPI, fluorescein isothiocyanate and TxRed channels. The images were acquired using NIS-Elements image analysis software AR 3.0 (Nikon). Finally, image processing was performed with Adobe Photoshop CS2. As a negative control, primary antibodies were excluded and no specific immunostaining was observed.

Morphometry. Morphometric measurements were performed using NIS-Elements image analysis software AR 3.0. The $\beta$-cell area was measured by acquiring at least five to eight non-overlapping images from each DAPI/insulin-stained section (six sections per rat) using a TE2000E microscope with a $10 \times$ objective. DAPI/insulin-stained images were acquired from all visible multicellular islets as small as ten cells per section and as large as 160 cells per section. The total $\beta$-cell area was determined on sections stained with insulin antibody and the number of $\beta$-cell nuclei was counted. The total $\beta$-cell area was divided by the total number of nuclei to calculate individual $\beta$-cell size.

Toxicity evaluation. The extract of $A$. officinalis was tested for acute toxicity (if any) in rats. To determine acute toxicity, a single oral administration of $A$. officinalis, at different doses of the extract $(0.25,0.5,1.0,1.5$ and $2.0 \mathrm{~g} / \mathrm{kg}$ body weight), was administered orally to the different groups of Wistar rats $(n 6)$ of both sexes. Mortality and general behaviours of the animals were observed continuously for the initial $4 \mathrm{~h}$ and intermittently for the next $6 \mathrm{~h}$, and then again at 24, 48 and $72 \mathrm{~h}$ following extract administration. After $28 \mathrm{~d}$ of the extract treatment, autopsy was performed for examining any abnormality in the liver, kidney, gastrointestinal tract, spleen and heart. Serum creatinine, alanine aminotransferase, aspartate aminotransferase were also determined to examine whether there was any sign of toxicity in the kidney and liver, respectively.

\section{Statistical analysis}

Statistical analyses were performed using the SPSS 12.0 statistical package for Windows (SPSS, Inc.). Data are expressed as means with their standard errors. The significance of the differences among the mean values was calculated using one-way ANOVA with Dunnett's and Bonferroni post boc tests, respectively. To compare data within the groups, a paired $t$ test (two-tailed) was performed. Morphometric data are expressed as medians with their ranges and compared using the Mann-Whitney $U$ test. $P<0.05$ was considered to be statistically significant.

\section{Results}

In vitro antioxidant and $\alpha$-glucosidase inhibitory activities of Asparagus officinalis

A. officinalis was evaluated for its radical-scavenging activity using DPPH. A. officinalis at a concentration of $0.5 \mathrm{mg} / \mathrm{ml}$ exhibited $86.8 \%$ radical-scavenging activity, as shown by a 
significant decrease in the absorbance of DPPH radicals. These results suggest that $A$. officinalis has potent antioxidant activity, as the positive control propyl gallate exhibited $91.4 \%$ radical-scavenging activity. A. officinalis exhibited only $32 \%$ inhibition of $\alpha$-glucosidase at a concentration of $0.5 \mathrm{mg} / \mathrm{ml}$. This inhibitory result suggests that this extract has a very little effect on delaying glucose absorption.

\section{Effect of the $28 d$ treatment of Asparagus officinalis extract on fasting blood glucose}

In the type 2 diabetic rats, fasting blood glucose was increased moderately after 3 months of STZ induction compared with the non-diabetic rats $(8.28(\operatorname{sem} 0.12) \mathrm{mmol} / \mathrm{l} v .4 .50$ (SEM $0 \cdot 23) \mathrm{mmol} / 1, P<0 \cdot 001 ;$ Fig. 1). These fasting blood glucose levels did not alter significantly during the experimental periods $(1-29 \mathrm{~d})$. After the A. officinalis extract treatment, there was a significant decrease in fasting blood glucose in a dose- and time-dependent manner. At the $250 \mathrm{mg} / \mathrm{kg}$ dose, the blood glucose levels were significantly decreased compared with the untreated diabetic rats with respect to the values of day $15(7.64 \quad(\mathrm{SEM} \quad 0 \cdot 11) \mathrm{mmol} / \mathrm{l} \quad v$. 8.39 (SEM $0 \cdot 20) \mathrm{mmol} / \mathrm{l}, P<0.001)$ and day $29(6.77$ (SEM 0.17) $\mathrm{mmol} / \mathrm{l}$ v. 8.51 (sem 0.23$) \mathrm{mmol} / \mathrm{l}, P<0.001)$. The $500 \mathrm{mg} / \mathrm{kg}$ dose decreased the blood glucose levels more efficiently compared with the $250 \mathrm{mg} / \mathrm{kg}$ dose. This dose $(500 \mathrm{mg} / \mathrm{kg})$ significantly decreased the blood glucose levels compared with the untreated diabetic rats with respect to the values of day 15 (6.54 (sEm 0.18) mmol/1 v. 8.39 (sem 0.20) mmol/1, $P<0.001$ ) and day $29(5.44(\operatorname{sem} 0 \cdot 13) \mathrm{mmol} / \mathrm{l} v .8 .51($ SEM $0 \cdot 23) \mathrm{mmol} / \mathrm{l}$, $P<0 \cdot 001)$.

In $A$. officinalis-treated rats, comparison of the blood glucose values with their baseline values (day 1) showed that both the doses of $A$. officinalis extract significantly decreased the fasting blood glucose levels in a time-dependent manner.
The blood glucose levels of the $\mathrm{Db}+\mathrm{AO}_{250}$ rats significantly decreased on day 15 as well as on day 29 with respect to their value of day 1 (day $1,8.44(\operatorname{sem} 0.20) \mathrm{mmol} / \mathrm{l}$; day 15 , $7 \cdot 64(\operatorname{sem} 0 \cdot 11) \mathrm{mmol} / \mathrm{l}$; day 29, $6 \cdot 77(\operatorname{sem} 0 \cdot 17) \mathrm{mmol} / \mathrm{l})$. The blood glucose levels of the $\mathrm{Db}+\mathrm{AO}_{500}$ group also significantly decreased on day 15 as well as on day 29 with respect to their value of day 1 (day $1,8.33$ (SEM 0.33$) \mathrm{mmol} / \mathrm{l}$; day 15 , $6.54(\operatorname{sem} 0 \cdot 18) \mathrm{mmol} / \mathrm{l}$; day 29, $5.44(\operatorname{sem~} 0 \cdot 13) \mathrm{mmol} / \mathrm{l})$. The standard drug GB also lowered the blood glucose levels significantly in a dose- and time-dependent manner.

\section{Effect of the $28 d$ treatment of Asparagus officinalis extract on fasting serum insulin}

Fasting serum insulin levels were significantly $(P<0.001)$ decreased in the untreated diabetic rats (49.28 (SEM 7·19) pmol/l) when compared with the control group (120.22 (sEM 18.02) pmol/l; Fig. 2). There was no significant change in serum insulin levels in the control and untreated diabetic rats during the experimental periods. When the diabetic rats were treated with $A$. officinalis extract at a dose of $250 \mathrm{mg} /$ $\mathrm{kg}$ for $28 \mathrm{~d}$, there was a slight, statistically non-significant, increase in serum insulin levels compared with the untreated diabetic rats $(62.23$ (SEM 6.30) pmol/1 v. 46.91 (SEM 6.92) $\mathrm{pmol} / \mathrm{l}, P=0 \cdot 133)$. However, the dose of $500 \mathrm{mg} / \mathrm{kg}$ significantly increased the serum insulin levels compared with the untreated diabetic rats $(77 \cdot 55$ (SEM 9.40) pmol/1 v. 46.91 (sem 6.92) pmol/1, $P<0.05$ ). GB also significantly increased the serum insulin levels $(81.47$ (SEM 7.62) pmol/l).

\section{Effect of the 28d treatment of Asparagus officinalis on fasting insulin:glucose ratio}

The insulin:glucose ratio was calculated from the fasting insulin and glucose values. It was found that 25.01 (SEM 0.66) pmol

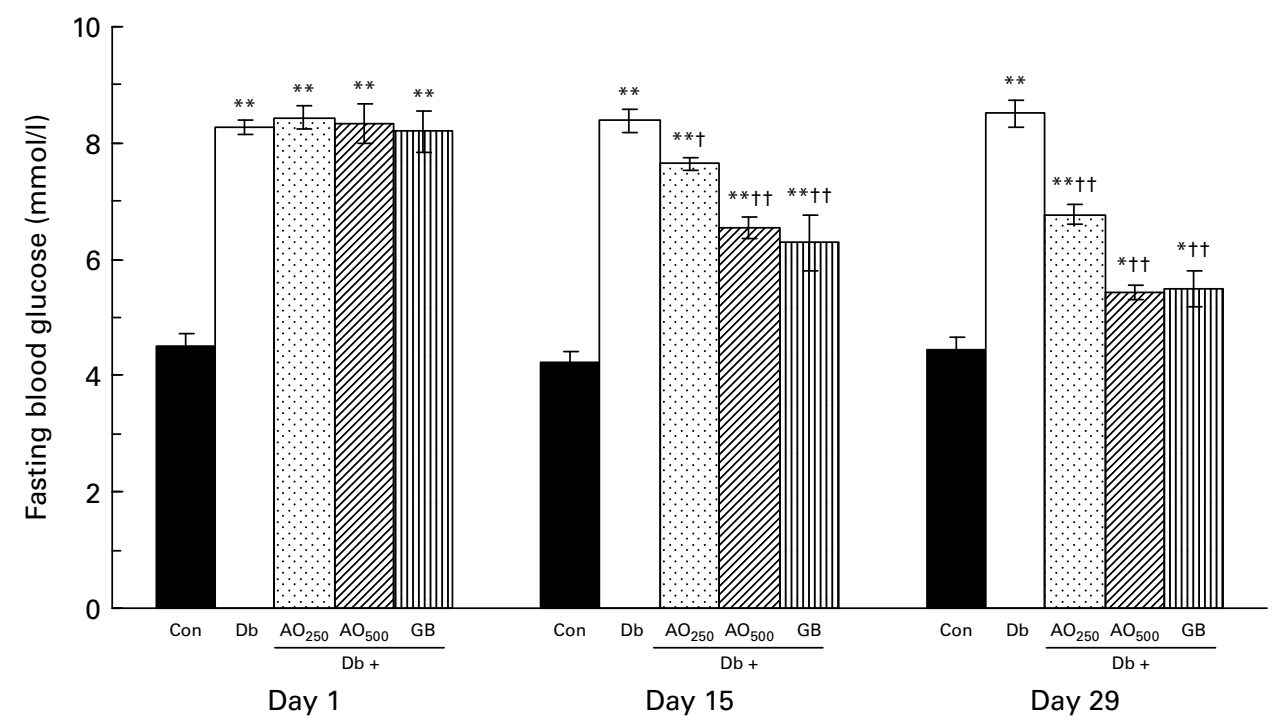

Fig. 1. Effect of Asparagus officinalis extract on fasting blood glucose (mmol/l) in type 2 diabetic rats. Values are means, with standard errors represented by vertical bars $\left(n\right.$ 6). Mean values were significantly different from those of the non-diabetic control rats: ${ }^{*} P<0.01$, ${ }^{* *} P<0.001$ (one-way ANOVA with Bonferroni post hoc test). Mean values were significantly different from those of the untreated diabetic rats: $\dagger P<0.01$, $\dagger+P<0.001$ (one-way ANOVA with Bonferroni post hoc test). Con, age-matched non-diabetic control; $\mathrm{Db}$, untreated diabetic rats; $\mathrm{AO}_{250}$, diabetic rats treated with $250 \mathrm{mg} / \mathrm{kg} A$. officinalis extract; $\mathrm{AO}$ 500, diabetic rats treated with $500 \mathrm{mg} / \mathrm{kg} A$. officinalis extract; GB, glibenclamide. 


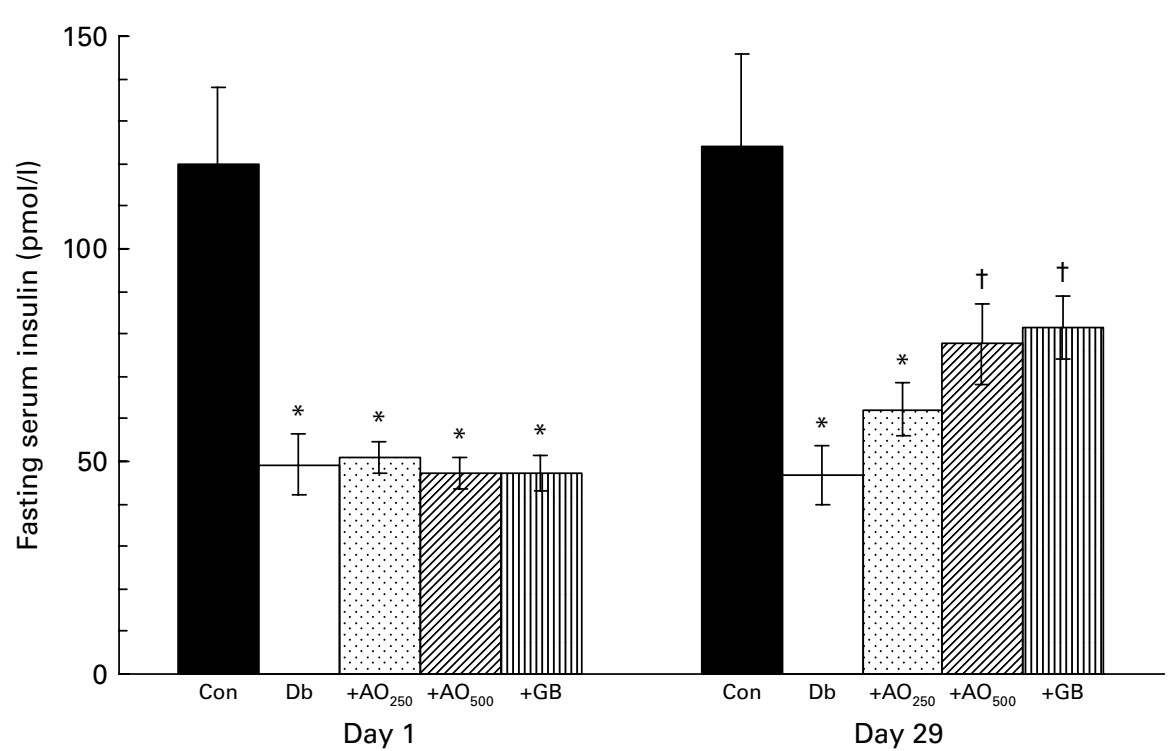

Fig. 2. Effect Asparagus officinalis extract on fasting serum insulin (pmol//) in type 2 diabetic rats. Values are means, with standard errors represented by vertical bars $(n 6)$. * Mean values were significantly different from those of the non-diabetic control rats $(P<0.001$; one-way ANOVA with Bonferroni post hoc test). $\dagger$ Mean values were significantly different from those of the untreated diabetic rats $(P<0.01$; one-way ANOVA with Bonferroni post hoc test). Con, age-matched non-diabetic control; $\mathrm{Db}$, untreated diabetic rats; $\mathrm{AO}_{250}$, diabetic rats treated with $250 \mathrm{mg} / \mathrm{kg} A$. officinalis extract; $\mathrm{AO}_{500}$, diabetic rats treated with $500 \mathrm{mg} / \mathrm{kg} A$. officinalis extract; GB, glibenclamide.

insulin/mmol glucose was available in the control rats; however, only 5.9 (sem 0.39) $\mathrm{pmol}$ insulin/mmol glucose was available in the diabetic rats (Fig. 3). After the $28 \mathrm{~d}$ treatment of A. officinalis extract, interestingly, there was a 1.7- and 2.6fold increase in insulin:glucose ratio in the $\mathrm{AO}_{250^{-}}$and $\mathrm{AO}_{500}$-treated diabetic rats compared with the untreated diabetic rats ( $\mathrm{Db}, 5.40(\operatorname{sem} 0.33) \mathrm{pmol} / \mathrm{mmol} ; \mathrm{Db}+\mathrm{AO}_{250}$, 9.15 (sEm 0.40$) \mathrm{pmol} / \mathrm{mmol} ; \mathrm{Db}+\mathrm{AO}_{500}, 14 \cdot 15$ (SEM 0.73 ) pmol/ $\mathrm{mmol})$. GB also increased the insulin:glucose ratio (14.72 (sEm 0.77 ) $\mathrm{pmol} / \mathrm{mmol}$ ) comparable to the value of $\mathrm{AO}_{500}$.

\section{Morphology of rat pancreas}

The results of typical H\&E staining obtained upon histological examination are shown in Fig. 4. In the control rats (Fig. 4(a)), islets of different sizes (small, medium and large) and shapes were found in all the pancreatic sections throughout the study period. On the contrary, diabetic pancreatic sections showed a reduction in pancreatic islet area and number (Fig. 4(b)). In the 250 and $500 \mathrm{mg} / \mathrm{kg}$ A. officinalis-treated diabetic groups, the pancreatic area and number was more than that observed

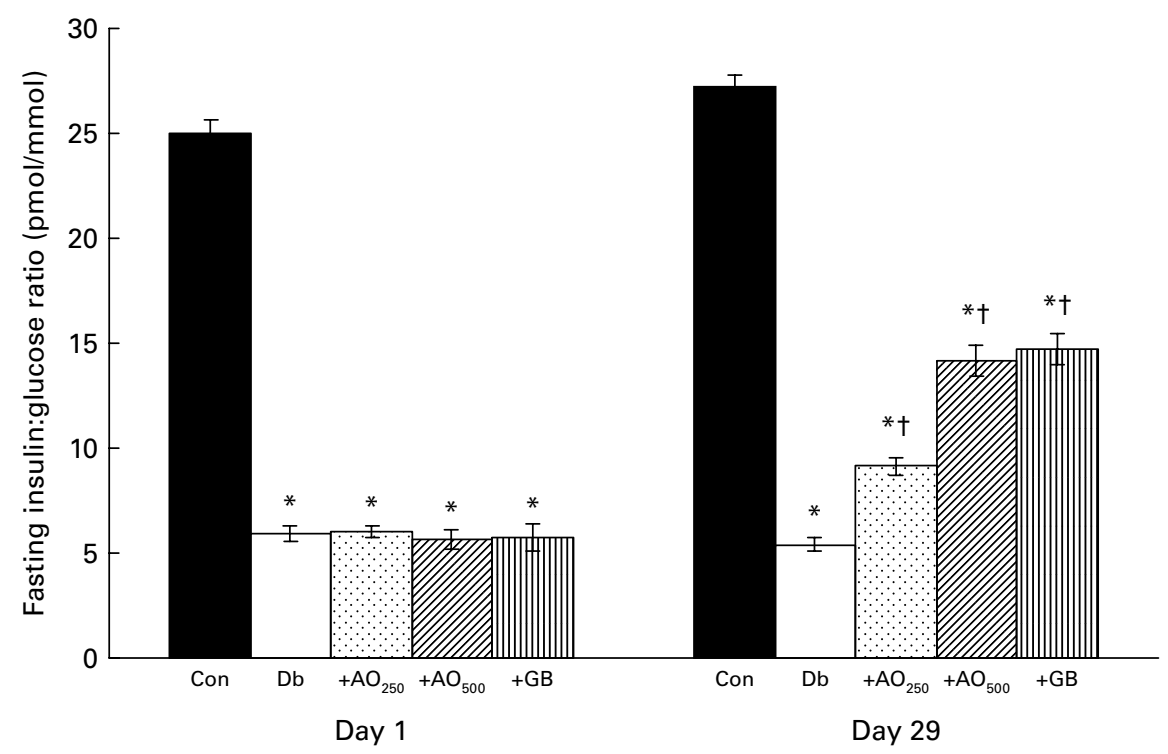

Fig. 3. Effect of Asparagus officinalis extract on fasting insulin:glucose ratio (pmol/mmol) in the experimental rats. Values are means, with standard errors represented by vertical bars $(n 6)$. * Mean values were significantly different from those of the non-diabetic control rats $(P<0 \cdot 001$; one-way ANOVA with Bonferroni post hoc test). † Mean values were significantly different from those of the untreated diabetic rats $(P<0.001$; one-way ANOVA with Bonferroni post hoc test). Con, age-matched non-diabetic control; $\mathrm{Db}$, untreated diabetic rats; $\mathrm{AO}_{250}$, diabetic rats treated with $250 \mathrm{mg} / \mathrm{kg} A$. officinalis extract; $\mathrm{AO}$ 500, diabetic rats treated with $500 \mathrm{mg} / \mathrm{kg}$ A. officinalis extract; GB, glibenclamide. 
in the untreated diabetic group (Fig. 4(c) and (d), respectively). The GB-treated group also showed improved islet size (Fig. 4(e)) similar to the $\mathrm{AO}_{500}$-treated group.

\section{Immunohistochemical studies on the pancreas}

Pancreatic islets stained for insulin, glucagon and DAPI fluorescence in the experimental rats are shown in Fig. 5. Insulin-positive cells were found abundantly in the islets of the control rats, and were located mostly in the centre of the islet (Fig. 5(a)). Different sizes of the total $\beta$-cell area were seen in the pancreas of the control rats. The ratio of the $\beta$ - and $\alpha$-cells was found to be $4: 1$. In the untreated diabetic rats, the insulin-positive cells were also found in the centre of the islet; however, the total number and the area of the $\beta$-cells were reduced significantly (Fig. 5(b)). In the diabetic rats, the large islets were absent and only a few $\beta$-cells containing the islets were visible. In contrast, when the diabetic rats were treated with $A$. officinalis extract for $28 \mathrm{~d}$, the average size of the total $\beta$-cell area and $\beta$-cell number was increased in both $\mathrm{AO}_{250^{-}}$and $\mathrm{AO}_{500^{-}}$-treated groups (Fig. 5(c) and (d), respectively). The GB-treated diabetic group also showed an increased total $\beta$-cell area and number of the $\beta$-cells (Fig. 5(e)) in the islets.
The glucagon-positive cells were found around the periphery of the insulin-positive cells in the control islets (Fig. 5(a)). In the diabetic rats, the distribution pattern of the glucagonpositive cells was similar to that of the control group (Fig. 5(b)); however, in some cases, the glucagon-stained cells were also seen scattered within the centre of the islets (data not shown). Interestingly, the number of the $\alpha$-cells relatively increased in the diabetic rats. The A. officinalis extract had no effect on the distribution of the glucagon-positive cells in the diabetic rats (Fig. 5(c) and (d)). GB also had no effect on the distribution of the glucagon-positive cells in the diabetic rats (Fig. 5(e)).

A representation of the nuclei staining of the non-diabetic control (Fig. 5(a)), diabetic control (Fig. 5(b)), A. officinalis 250 and $500 \mathrm{mg} / \mathrm{kg}$ (Fig. 5(c) and (d), respectively), and GBtreated rats (Fig. 5(e)) is also shown for comparison.

\section{Morphometric studies on the pancreas}

In the control rats, the total $\beta$-cell area/islet, expressed as medians, was 18420 (range 5375-37543) $\mu^{2}{ }^{2}$, whereas in the diabetic rats, it was decreased significantly (6099 (range 316515391) $\mu \mathrm{m}^{2}, \quad P<0.001$; Table 1$)$. The $\beta$-cell area was 8918 (range 3123-15068) and 10205 (range 3065-17575) $\mu \mathrm{m}^{2}$ in
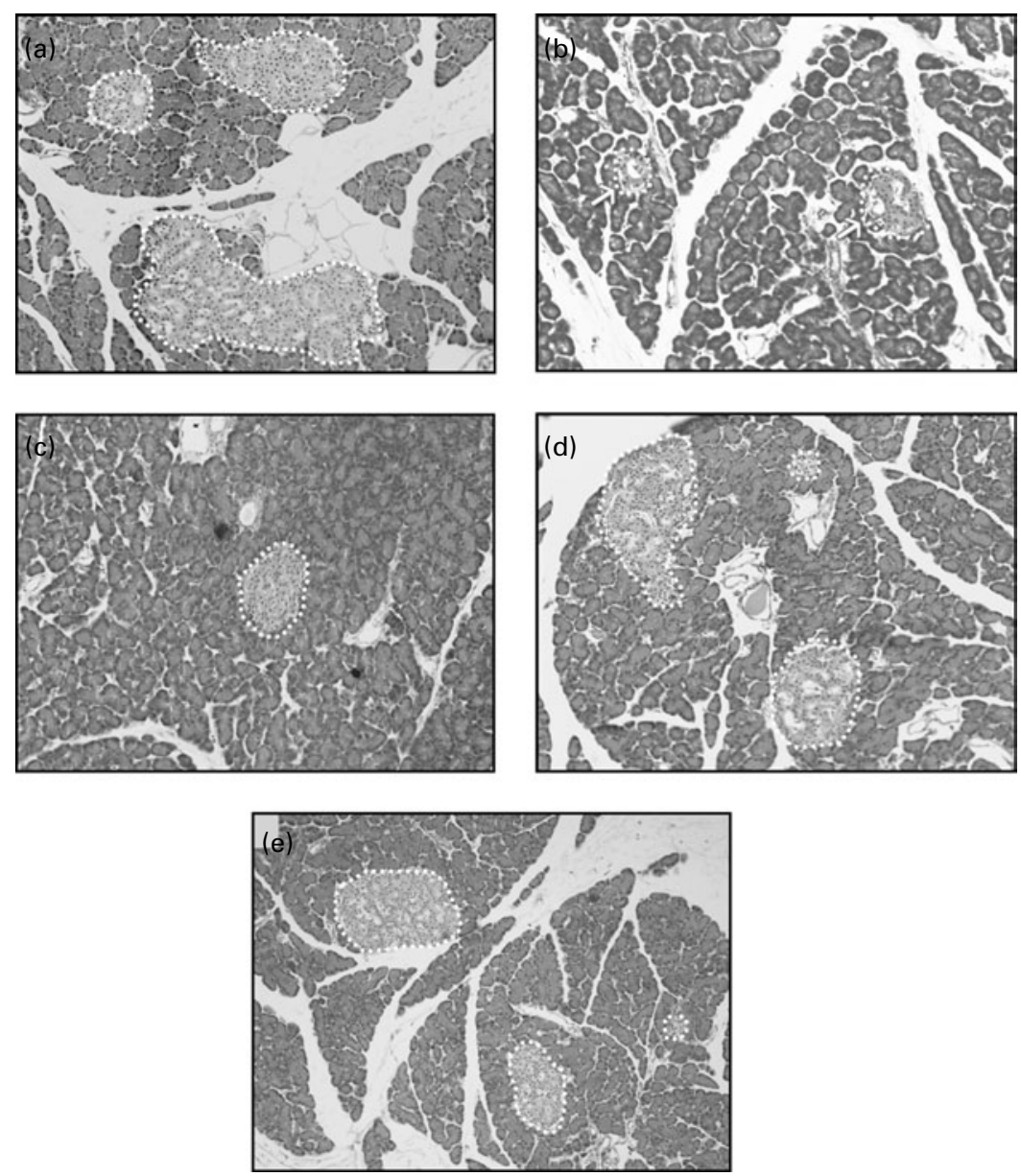

Fig. 4. (a-e) Light microscopic study of the pancreatic islets $(10 \times)$ in the different experimental groups: (a) non-diabetic control; (b) untreated diabetic; (c) Asparagus officinalis $250 \mathrm{mg} / \mathrm{kg}$, (d) A. officinalis $500 \mathrm{mg} / \mathrm{kg}$; (e) glibenclamide-treated. White dotted lines represent the islet area and the arrow indicates the small islets. 

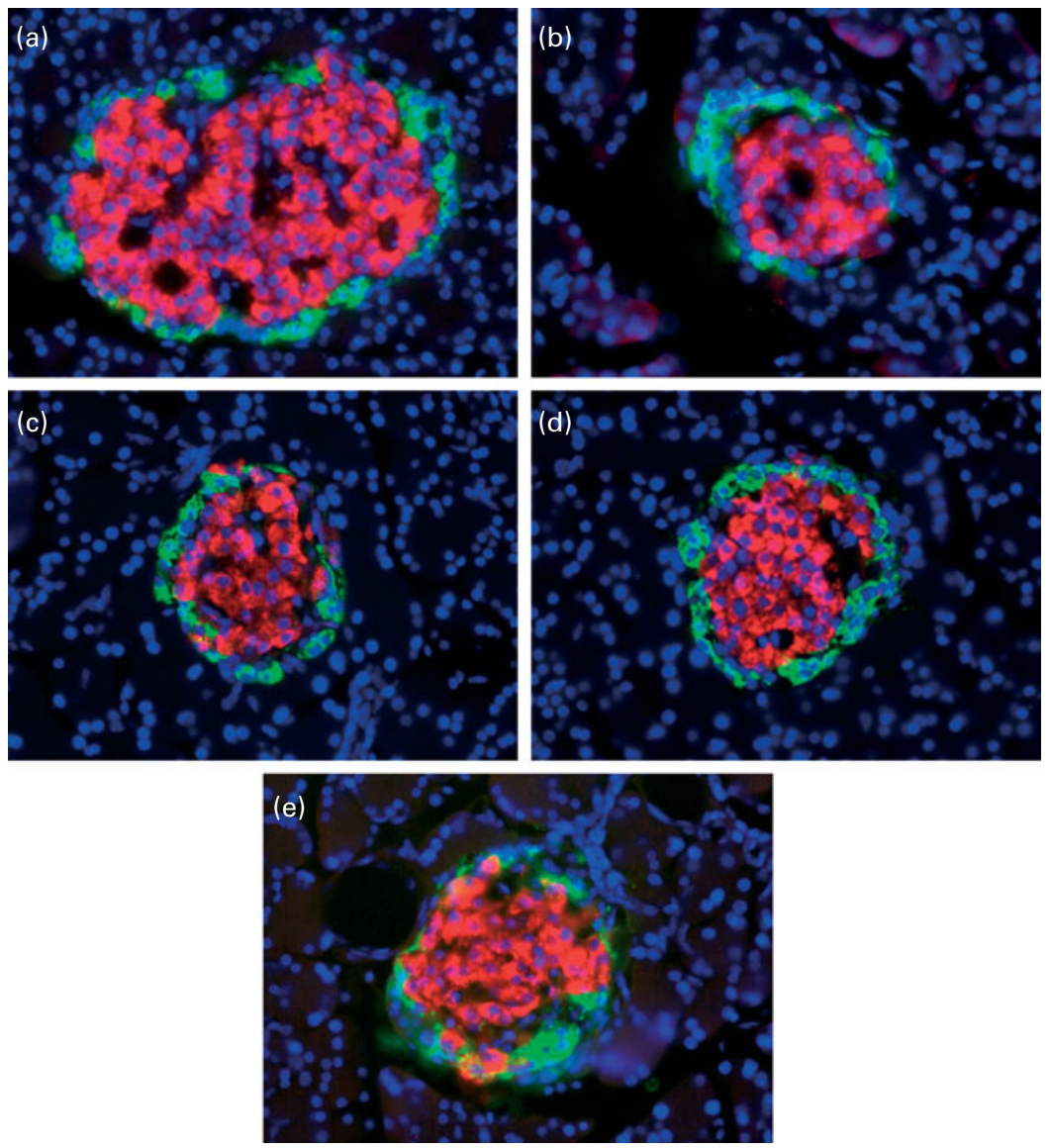

Fig. 5. (a-e) Mutichannel fluorescence microscopic study of insulin-positive $\beta$-cells (red), glucagon-positive $\alpha$-cells (green) and nuclei (blue) of the pancreatic islets $(20 \times)$ of the different experimental groups: (a) non-diabetic control; (b) untreated diabetic; (c) Asparagus officinalis $250 \mathrm{mg} / \mathrm{kg}$, (d) A. officinalis $500 \mathrm{mg} / \mathrm{kg}$; (e) glibenclamide-treated.

the $\mathrm{AO}_{250^{-}}$and $\mathrm{AO}_{500^{-}}$treated rats, respectively. These results indicate that $A$. officinalis can markedly $(P<0.001)$ increase the total $\beta$-cell area. In the control rats, the number of $\beta$-cells per islet, expressed as medians, was 111 (range 22-160). However, the $\beta$-cell number decreased significantly $(P<0.001)$ in the diabetic rats (28 (range 11-64) v. 111 (range 22-160), $P<0.001)$. There was a significant increase in $\beta$-cell number in the $\mathrm{AO}_{250}$-treated (35 (range 18-58)) and $\mathrm{AO}_{500}$-treated (44 (range 14-98)) rats, respectively. Although the $\beta$-cell area and number decreased significantly in the diabetic rats, very interestingly, the individual $\beta$-cell size, expressed as medians, was increased in the diabetic rats compared with the control rats (221 (range 85-699) $\mu \mathrm{m}^{2}$ v. 202 (range 44-475) $\mu \mathrm{m}^{2}$, $P<0.060)$. The $P$ value is just outside the border of the significance level, suggesting that hyperplasia of the $\beta$-cell may have occurred in this type 2 diabetic rat model. The individual $\beta$ cell size was increased (very close to the significance level) in the $\mathrm{AO}_{250}$-treated rats compared with the control rats (222 (range 79-460) $\mu \mathrm{m}^{2}$ v. 202 (range 44-475) $\mu \mathrm{m}^{2}, P<0.065$ ). There was no significant change in individual $\beta$-cell size in the

Table 1. Morphometric analysis of the pancreatic islets in the experimental rats

(Median values with their ranges; sixty islets/rats; $n 6-9$ )

\begin{tabular}{|c|c|c|c|c|c|c|}
\hline \multirow[b]{2}{*}{ Groups } & \multicolumn{2}{|c|}{$\beta$-Cell area/islet $\left(\mu \mathrm{m}^{2}\right)$} & \multicolumn{2}{|c|}{$\beta$-Cell no./islet } & \multicolumn{2}{|c|}{$\beta$-Cell size $\left(\mu \mathrm{m}^{2}\right)$} \\
\hline & Median & Range & Median & Range & Median & Range \\
\hline Con & 18420 & $5375-37543$ & 111 & $22-160$ & 202 & $44-475$ \\
\hline $\mathrm{Db}$ & $6099^{\star}$ & $3165-15391$ & $28^{*}$ & $11-64$ & 221 & $85-699$ \\
\hline $\mathrm{Db}+\mathrm{AO}_{250}$ & $8918^{*} \dagger$ & $3123-15068$ & $35^{\star} \dagger$ & $18-58$ & 222 & $79-660$ \\
\hline $\mathrm{Db}+\mathrm{AO}_{500}$ & $10205^{*} \dagger \dagger$ & $3065-17575$ & $44^{*}+\dagger$ & $14-98$ & 209 & $66-595$ \\
\hline $\mathrm{Db}+\mathrm{GB}$ & $10177^{*}+t$ & $3071-16060$ & $47^{*}+t$ & $19-98$ & 205 & $45-609$ \\
\hline
\end{tabular}

Con, age-matched non-diabetic control; $\mathrm{Db}$, untreated diabetic rats; $\mathrm{AO}_{250}$, diabetic rats treated with $250 \mathrm{mg} / \mathrm{kg}$ Asparagus officinalis extract; $\mathrm{AO}_{500}$, diabetic rats treated with $500 \mathrm{mg} / \mathrm{kg}$ Asparagus officinalis extract; GB, glibenclamide.

${ }^{*}$ Median values were significantly different from those of the non-diabetic control $(P<0.001$; Mann-Whitney $U$ test).

Median values were significantly different from those of the untreated diabetic: $\uparrow P<0.05, \dagger \dagger P<0.01$ (Mann-Whitney $U$ test) 
$\mathrm{AO}_{500^{-}}$or GB-treated diabetic rats. These results suggest that $\beta$-cell hypertrophy is the phenomenon of this rat model; however, it is the hyperplasia, not hypertrophy, of the $\beta$-cell in the $A$. officinalis-treated diabetic rats that might have contributed to the anti-diabetic effect.

\section{Effect of the $28 d$ treatment of Asparagus officinalis extract on total antioxidant status}

Changes in TAS in each group of rats are shown in Fig. 6. A significant decrease in TAS was found in the untreated diabetic rats compared with the control rats $(1.19$ (SEM 0.06) mmol/1 $v$. $1.86(\operatorname{sem~} 0.08) \mathrm{mmol} / 1, P<0 \cdot 01)$. A. officinalis extract at a dose of 250 or $500 \mathrm{mg} / \mathrm{kg}$ for $28 \mathrm{~d}$ significantly increased the TAS in a dose-dependent manner $\left(\mathrm{AO}_{250}, 1.61\right.$ (sEM 0.10) mmol/l; $\mathrm{AO}_{500}, 1.88$ (SEM $\left.\left.0 \cdot 21\right) \mathrm{mmol} / \mathrm{l}\right)$. In the $500 \mathrm{mg} / \mathrm{kg}$ A. officinalis-treated rats, TAS was found even more than that of the control rats. A mild but significant increase in TAS (1.55 (SEM $0 \cdot 02) \mathrm{mmol} / \mathrm{l}$ ) was also found in the GB-treated rats.

\section{Discussion}

The present study demonstrated that administration of a methanolic extract of $A$. officinalis seeds to n-STZ nonobese type 2 diabetic rats decreased blood glucose levels in a dose- and time-dependent manner (Fig. 1). Preliminary in vitro experiments for $\alpha$-glucosidase inhibitory activity showed that $A$. officinalis extract has a very little effect on

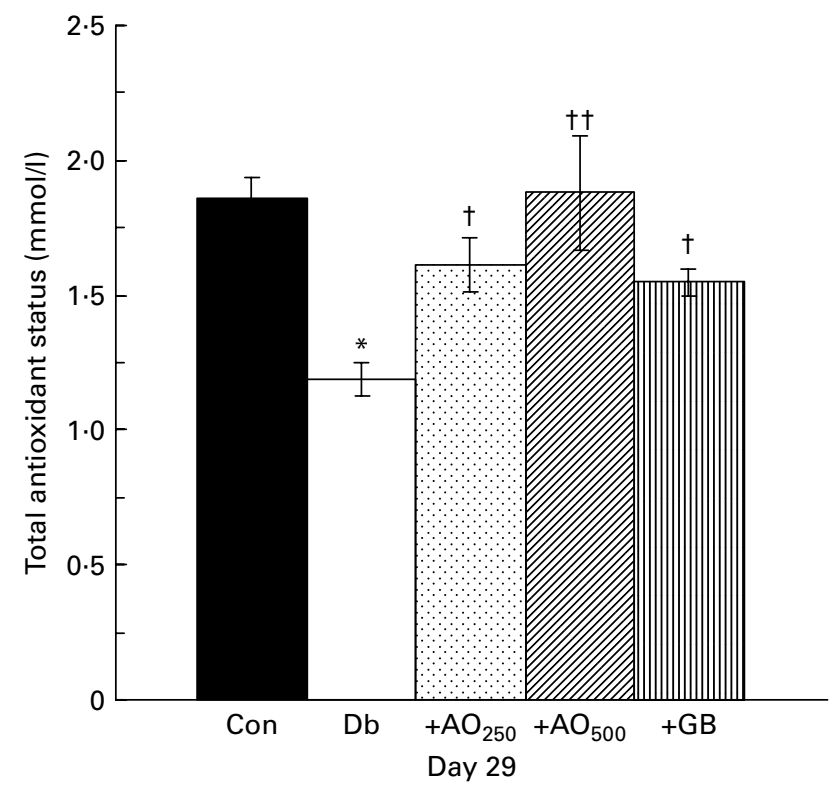

Fig. 6. Effect of Asparagus officinalis extract on the total antioxidant status $(\mathrm{mmol} / \mathrm{l})$ in the experimental rats. Values are means, with standard errors represented by vertical bars $(n 6)$. * Mean values were significantly different from those of the non-diabetic control rats $(P<0.001$; one-way ANOVA with Bonferroni post hoc test). Mean values were significantly different from those of the untreated diabetic rats: $\dagger P<0.05$, $\dagger \dagger P<0.001$ (one-way ANOVA with Bonferroni post hoc test). Con, age-matched non-diabetic control; $\mathrm{Db}$, untreated diabetic rats; $\mathrm{AO}_{250}$, diabetic rats treated with $250 \mathrm{mg} / \mathrm{kg} A$. officinalis extract; $\mathrm{AO}_{500}$, diabetic rats treated with $500 \mathrm{mg} / \mathrm{kg} A$. officinalis extract; GB, glibenclamide. $\alpha$-glucosidase, suggesting that $A$. officinalis may have a very little to no effect on delaying glucose absorption.

Serum insulin levels were significantly decreased in the untreated diabetic rats (Fig. 2). Pathological changes in serum insulin levels in diabetes reflect abnormalities in $\beta$ cell function or structure. The decrease in the $\beta$-cell function and size of the islets (Figs. 4 and 5) is a clear indication that the n-STZ type 2 diabetes in these rats was not due to insulin resistance but was because of $\beta$-cell dysfunction, which is the major pathophysiology of non-obese type 2 diabetic subjects in the Indo-Pak region ${ }^{(35,36)}$.

The untreated diabetic rats had higher blood glucose levels and lower insulin levels than the non-diabetic controls (Figs. 1 and 2 , respectively). Interestingly, the $A$. officinalis extract treatment significantly improved serum insulin levels as well as the insulin:glucose ratio in the diabetic rats (Figs. 2 and 3, respectively). The increased serum insulin levels may be related to the up-regulation of insulin synthesis by the $\beta$-cells, enhanced insulin secretion or insulin release from the pancreatic $\beta$-cells. Previously, it has been reported that the ethanolic extract of $A$. racemosus roots increased insulin secretion in the isolated islets of rats in vitro ${ }^{(37)}$ Thus, the control of blood glucose levels is most probably due to the enhanced insulin secretion from the pancreatic $\beta$-cells in the $A$. officinalis-treated diabetic rats.

The $A$. officinalis treatment improved the size of the islets in the diabetic rats (Fig. 4). The $\beta$-cell is the most abundant cell type in the endocrine pancreas, and $\beta$-cell number is the most important factor that determines the islet area. It has been reported elsewhere that $\alpha$-cells increased in diabetic rats and the distribution pattern of the $\alpha$ - and $\beta$-cells changed in STZ-induced diabetic rats ${ }^{(38,39)}$. In the present study, it was not clear from H\&E staining whether the increased size of the islets was due to the $\beta$ - or $\alpha$-cells (Fig. 4). To determine this, we stained the same pancreatic sections with insulin and glucagon antibodies to observe the insulin-positive $\beta$ cells and glucagon-positive $\alpha$-cells simultaneously. The immunohistochemical data revealed that it was the $\beta$-cell that played the major role for the increased size of the islets (Fig. 5).

A. officinalis improved $\beta$-cell function in the diabetic rats. However, it was not clear whether this improvement of $\beta$ cell function was due to the hyperplasia or hypertrophy of the $\beta$-cells. The immunohistochemical and morphometric studies suggest that hyperplasia rather than hypertrophy in the A. officinalis-treated rats (Fig. 5 and Table 1) was responsible for the improvement in $\beta$-cell function. Therefore, the increased number of $\beta$-cells may have a direct role in controlling the blood glucose levels in this diabetic rat model. Furthermore, the high-resolution insulin immunohistochemical data revealed that most of the $\beta$-cells were degranulated in the treatment group, suggesting that $A$. officinalis stimulated the release of insulin from the pancreatic $\beta$-cells (data not shown). Therefore, the present biochemical results along with the immunohistochemical findings further support that the anti-diabetic activity of $A$. officinalis may be due to the enhanced insulin secretion and/or insulin release.

The $\beta$-cell number in the pancreatic islets of the $A$. officinalis-treated rats was significantly higher than that of the 
untreated diabetic rats (Table 1). This suggests that $A$. officinalis may have a role in the regeneration or revitalisation of the $\beta$-cells or in the recovery of the partially damaged $\beta$-cells. A number of other plants have also been observed to exert anti-diabetic activity through these mechanisms ${ }^{(40-42)}$.

Although the A. officinalis extract showed potent antioxidant activity in vitro, we asked whether the antioxidant had any role in the mechanism of the anti-diabetic property of the $A$. officinalis extract. In support to the antioxidant activity of the extract, we found that TAS was increased significantly in the A. officinalis-treated rats (Fig. 6). The mechanisms responsible for the increased antioxidant status of $A$. officinalis are not clear. However, a strong correlation between the antioxidant activity and the total phenol content of asparagus has been reported, suggesting that phenols could be mainly responsible for the antioxidant activity, as observed for other vegetables $^{(43,44)}$. The antioxidant activity of $A$. officinalis extract may prevent STZ-induced oxidant damage to the $\beta$ cells. Thus, it may also suggest that the anti-diabetic activity may partially be due to the antioxidant property of the extract. Studies are ongoing in our laboratory to elucidate this hypothesis.

In conclusion, we have shown that long-term administration of $A$. officinalis has anti-diabetic effects on non-obese type 2 diabetic rats. The anti-diabetic activity appears mainly due to the enhanced insulin secretion and the modulation of pancreatic $\beta$-cell function. The antioxidant may also play an indirect role in the anti-diabetic activity of $A$. officinalis. Altogether, these findings indicate that asparagus may be an effective therapeutic strategy for the management of non-obese type 2 diabetes. Further experiment and clinical studies are required to explore the additional mechanisms and establish its clinical utility.

\section{Acknowledgements}

This study was supported by a grant (5-9/3394/PAS/) from the Pakistan Academy of Sciences (PAS), Islamabad, Pakistan. We would like to appreciate Professor Muhammad Iqbal Choudhary for his encouragement. We are thankful to Dr Suad Naheed and Dr Sajjad Ali for the in vitro assays, and Maryam Bano for the GB experiments. R. M. H. and N. K. designed the study. R. M. H. conducted the research, analysed the data and wrote the manuscript. R. M. H. and N. K. analysed the histological and immunohistochemical changes. S. C. was involved in animal handling, feeding the extract to the animals and blood glucose estimation. All the authors read and approved the final manuscript. None of the authors has conflicts of interest.

\section{References}

1. Bazzano LA, He J, Ogden LG, et al. (2002) Fruit and vegetable intake and risk of cardiovascular disease in US adults: the first National Health and Nutrition Examination Survey Epidemiologic Follow-up Study. Am J Clin Nutr 76, 93-99.
2. Carter P, Gray LJ, Troughton J, et al. (2010) Fruit and vegetable intake and incidence of type 2 diabetes mellitus: systematic review and meta-analysis. BMJ 341, c4229.

3. Williams DE, Wareham NJ, Cox BD, et al. (1999) Frequent salad vegetable consumption is associated with a reduction in the risk of diabetes mellitus. J Clin Epidemiol 52, 329-335.

4. Vinson JA, Hao Y, Su X, et al. (1998) Phenol antioxidant quantity and quality in foods: vegetables. J Agric Food Chem 46, 3630-3634.

5. Pellegrini N, Serafini M, Colombi B, et al. (2003) Total antioxidant capacity of plant foods, beverages and oils consumed in Italy assessed by three different in vitro assays. J Nutr 133, 2812-2819.

6. Pant G, Panwar MS, Negi DS, et al. (1988) Spirostanol glycoside from fruits of Asparagus officinalis. Phytochemistry 27, 3324-3325.

7. Shao Y, Poobrasert O, Kennelly EJ, et al. (1997) Steroidal saponins from Asparagus officinalis and their cytotoxic activity. Planta Med 63, 258-262.

8. Shiomi N, Yamada J \& Izawa MA (1979) Novel pentasaccharide in the roots of asparagus (Asparagus officinalis L.). Agric Biol Chem 43, 1375-1377.

9. Shiomi N (1981) Two novel hexasaccharides from the roots of Asparagus officinalis. Phytochemistry 20, 2581-2583.

10. Fukushi E, Onodera S, Yamamori A, et al. (2000) NMR analysis of tri- and tetrasaccharides from asparagus. Magn Reson Chem 38, 1005-1011.

11. Terada K, Honda C, Suwa K, et al. (1995) Acetylenic compounds isolated from cultured cells of Asparagus officinalis. Chem Pharm Bull 43, 564-566.

12. Yanagawa H, Kato T, Kitahara Y, et al. (1972) Asparagusic acid, dihydroasparagusic acid, and $S$-acetyldihydroasparagusic acid, new plant growth inhibitors in etiolated young Asparagus officinalis. Tetrahedron Lett 13, 2549-2552.

13. Yanagawa H, Kato T \& Kitahara Y (1973) Asparagusic acid S-oxides, new plant growth regulators in etiolated young asparagus shoots. Tetrahedron Lett 14, 1073-1075.

14. Kasai T, Hirakuri Y \& Sakamura S (1983) Two cysteine derivatives in asparagus shoots. Phytochemistry 22, 2563-2564.

15. Matsubayashi Y \& Sakagami Y (1996) Phytosulfokine, sulfated peptides that induce the proliferation of single mesophyll cells of Asparagus officinalis L. Proc Natl Acad Sci U $S A$ 93, 7623-7627.

16. Gang ZZ, Li LZ \& Xian LX (1997) Study on the isolation, purification and antioxidation properties of polysaccharides from Spirulina maxima. Acta Botanica Sinica 39, 77-81.

17. Liu SX, Chen Y, Zhou M, et al. (1997) Protective effect of the polysaccharide kreskin on inhibition of lipopolysaccharideinduced nitric oxide production in macrophages caused by oxidized low-density lipoprotein. Med Sci Res 25, 507-509.

18. Zeng N, Meng X \& Zhang Y (1997) Studies on the antioxidative effect of constituents of Herba epimedii (ESPS). Zhongguo Zhongyao Zazhi 22, 46-48.

19. Said O, Khalil K, Fulder S, et al. (2002) Ethnopharmacological survey of medicinal herbs in Israel, the Golan Heights and the West Bank region. J Ethnopharmacol 83, 251-265.

20. Shao Y, Chin CK, Ho CT, et al. (1996) Anti-tumor activity of the crude saponins obtained from asparagus. Cancer Lett $\mathbf{2 4}$, $31-36$.

21. Wang $\mathrm{H} \& \mathrm{Ng} \mathrm{TB}$ (2001) Isolation of a novel deoxyribonuclease with antifungal activity from Asparagus officinalis seeds. Biochem Biophys Res Commun 23, 120-124.

22. Balansard S \& Rayband M (1987) Diuretic action of Asparagus officinalis. Crit Rev Soc Biol 126, 954-956.

23. Thatte UM \& Dahanukar SA (1988) Comparative study of immunomodulating activity of Indian medicinal plants, 
lithium carbonate and glucan. Methods Find Exp Clin Pharmacol 10, 639-644.

24. Rege NN, Thatte UM \& Dahanukar SA (1999) Adaptogenic properties of six rasayana herbs used in Ayurvedic medicine. Phytother Res 3, 275-291.

25. Rodríguez R, Jaramillo S, Rodríguez G, et al. (2005) Antioxidant activity of ethanolic extracts from several asparagus cultivars. J Agric Food Chem 29, 5212-5217.

26. Ali SI \& Khan SW (2009) Asparagaceae. In Flora of Pakistan, no. 217, pp. 1-23 [SI Ali and M Qaiser, editors]. Karachi: BCC\&T Press.

27. Zhao J, Zhang W, Zhu X, et al. (2011) The aqueous extract of Asparagus officinalis L. by-product exerts hypoglycaemic activity in streptozotocin-induced diabetic rats. J Sci Food Agric 91, 2095-2099.

28. Portha B, Blondel O, Serradas P, et al. (1989) The rat models of non-insulin dependent diabetes induced by neonatal streptozotocin. Diabetes Metab 15, 61-75.

29. Kodama T, Iwase M, Nunoi K, et al. (1993) A new diabetes model induced by neonatal alloxan treatment in rats. Diabetes Res Clin Pract 20, 183-189.

30. Arulmozhi DK, Veeranjaneyulu A \& Bodhankar SL (2004) Neonatal streptozotocin-induced rat model of type 2 diabetes mellitus: a glance. Indian J Pharmacol 36, 217-221.

31. Portha B, Movassat J, Cuzin-Tourrel C, et al. (2007) Neonatally streptozotocin-induced (n-STZ) diabetic rats: a family of type 2 diabetes models. In Animal Models of Diabetes, 2nd ed., pp. 223-250 [E Shafrir, editor]. Boca Raton, FL: CRC Press.

32. Fenglin H, Ruili L, Bao H, et al. (2004) Free radical scavenging activity of extracts prepared from fresh leaves of selected Chinese medicinal plants. Fitoterapia 75, 14-23.

33. Atta-ur-Rahman, Zareen S, Choudhary MI, et al. (2008) Alpha-glucosidase inhibitory activity of triterpenoids from Cichorium intybus. J Nat Prod 71, 910-913.

34. Bonner-Weir S, Trent DF, Honey RN, et al. (1981) Responses of neonatal rat islets to streptozotocin: limited B-cell regeneration and hyperglycemia. Diabetes 30, 64-69.
35. Roy MN, Biswas KB, Siddiqua N, et al. (2007) Determinants of insulin secretion and sensitivity in Bangladeshi type 2 diabetic subjects. Metab Syndr Relat Disord 5, 275-281.

36. Karim MR, Zinnat R, Akter S, et al. (2011) Characterization of insulin secretion in type 2 diabetic subjects. Bang J Med Biochem 2, 21-25.

37. Hannan JM, Marenah L, Ali L, et al. (2007) Insulin secretory actions of extracts of Asparagus racemosus root in perfused pancreas, isolated islets and clonal pancreatic beta-cells. J Endocrinol 192, 159-168.

38. Papaccio G \& Mezzogiorno M (1992) Morphological aspect of glucagon and somatostatin islet cells in diabetic biobreeding and low-dose streptozotocin-treated Wistar rats. Pancreas 4, 289-294.

39. Pons P \& Aoki A (1995) Differential proliferation of somatostatin and glucagon cells in rat pancreatic islets submitted to different stimuli. Ann Anat 177, 221-227.

40. Singh N \& Gupta M (2007) Regeneration of beta cells in islets of Langerhans of pancreas of alloxan diabetic rats by acetone extract of Momordica charantia (Linn.) (bitter gourd) fruits Indian J Exp Biol 45, 1055-1062.

41. Shanmugasundaram ER, Gopinath KL, Radha SK, et al. (1990) Possible regeneration of the islets of Langerhans in streptozotocin-diabetic rats given Gymnema sylvestre leaf extracts. J Ethnopharmacol 30, 265-279.

42. Hafizur RM, Kabir N \& Chishti S (2011) Modulation of pancreatic $\beta$-cells in neonatally streptozotocin-induced type 2 diabetic rats by the ethanolic extract of Momordica charantia fruit pulp. Nat Prod Res 25, 353-367.

43. Gardner PT, White TAC, McPhail DB, et al. (2000) The relative contributions of vitamin $\mathrm{C}$, carotenoids and phenolics to the antioxidant potential of fruit juices. Food Chem $\mathbf{6 8}$, 471-474

44. Martinez-Valverde I, Periago MJ, Provan G, et al. (2002) Phenolic compounds, lycopene and antioxidant activity in commercial varieties of tomato (Lycopersicon esculentum). J Sci Food Agric 82, 323-330. 